\title{
Chemiresistive Polyaniline-Based Gas Sensors. A Mini Review
}

\author{
Ilaria Fratoddi..$^{\ddagger}$, Iole Venditti. ${ }^{\ddagger}$, Cesare Cametti..$^{\natural}$ and Maria Vittoria \\ Russo ${ }^{\ddagger}$ \\ $¥$ Department of Chemistry, University of Rome "La Sapienza", Rome, Italy \\ ${ }^{\natural}$ Department of Physics, University of Rome "La Sapienza" Rome, Italy and CNR-INFM \\ SOFT Unita' di Roma1
}

\begin{abstract}
This review focuses on some recent advances made in the field of gas sensors based on polyaniline [PANI], a conducting polymer with excellent electronic conductivity and electrochemical properties. Conducting polymers represent an important class of organic materials with an enhanced resistivity towards external stimuli. Among them, PANI polymers have attracted wide interest because of the versatility in their use, combined with the easy of synthesis, high yield and good environmental stability, together with a favorable response to guest molecules at room temperature. Moreover, PANI can be shaped into various structures with different morphologies and the possibility of obtaining nanofibers, in addition to thin films, has opened a rapid development of ultrasensitive chemical sensors, with improved processability and functionality. This review provides a brief description of the current status of gas chemiresistive sensors based on polyaniline and highlights the properties and applications of these devices in diverse range of applications.
\end{abstract}

Keywords:

Gas sensors; Polyaniline; Chemiresistive response.

\section{Introduction}

Chemical sensors are generally based on the concomitant presence of two elements, a recognition element (active element) sensitive to stimuli produced by various chemical compounds (analytes) and a transduction element, that produces a signal whose magnitude is related, through a known relationship, to the concentration of the analyte itself. 
The use of conducting polymers as active element in gas sensors has a long story and the first attempts date back to the early 1980s [1]. The mechanism of conduction in such polymers is very complex since these materials exhibit electrical conductivity across a range of about fifteen orders of magnitude, ascribed to the formation of non linear defects such as solitons, polarons or bipolarons, formed during either the doping process or the polarization of the monomer units [2].

Conducting polymers, in comparison for example with metal oxides, present numerous advantages such as a high sensitivity, a short response time, room temperature operation, the possibility of tuning both chemical and physical properties by using different substituents. The chemical structures of some typical conducting polymers are shown in Fig. 1.

In last few years, a variety of sensors have been formulated using conducting polymers in different transduction modes, which can be roughly divided into five different classes [3, 4], based upon different operating modes. They are $i$ ): conductometric mode (changes in electrical conductivity), ii) potentiometric mode (changes in the chemical potential without current flow) iii) amperometric mode (measurement of the current generated by the redox reaction of an analyte at a sensing (working) electrode), iv) colorimetric mode (changes in optical absorption) and $v$ ) gravimetric mode (change in the polymer weight, as a result of analyte-polymer interaction).

In the present review, we will consider solely the first of these modes, where the recognition element of gas sensing is the change of the electrical properties, mainly in the electrical conductivity, of the conducting polymer. This change can be induced by the charge-transfer with the gas molecules or, in a rather indirect way, by the mass change due to the physical adsorption of the gas molecules.

Nanostructured materials, especially based on conducting polymers have received in the recent years great attention for a variety of applications including chemical and biological sensors [5, 6, 7, 8, 9, 10, 11, 12, 13, 14, 15, 16].

Polymer-based chemical sensors have high sensitivity (potentially single molecule sensitivity) due to large surface to volume ratio, fast response, lower power consumption, small size and lightweight and, moreover, compactness in size and mass and easy integration to the existing electronic system.

A common characteristic is that these polymers in pure form have a rather low conductivity, of the order of $10^{-10} \mathrm{mho} / \mathrm{cm}$, which easily can be increased to values of the order of $10^{3}-10^{5} \mathrm{mho} / \mathrm{cm}$ by a doping process. In general, the removing of some electrons (by chemical or electrochemical oxidation) 
leaves the polymer backbone charged and the cation radical acts as a charge carrier.

By now, there has been a large amount of works dealing with gas sensors based on different conducting polymers, some of them from our group [17, $18,19,20,21,22,23,24]$, and numerous and comprehensive reviews that focus on different aspects of gas sensors are available $[25,26]$.

The present review pays attention to a particular conducting polymer, probably one of the oldest known synthetic organic polymers, polyaniline [PANI] [27], that presents a rather different doping process in comparison with other conducting polymers and, at the same time, has been largely employed as sensing material for different vapors like methanol, ethanol, acetone, benzene and various gases like $\mathrm{NH}_{3}$ and hydrogen $[28,29]$.

Among conducting polymers, PANI has received wide-spread attention because of its outstanding properties including simple and reversible dopingdedoping chemistry, stable electrical conduction mechanisms, high environmental stability and ease of synthesis, which drives it towards potential electrical device applications. Moreover, PANI shows diverse chemical structures and different response mechanisms upon exposure to different gases $[30,31,32,33,34,35]$.

The main aim of this review is to present the state-of-the-art of these promising gas sensors, with particularly attention to the quality parameters of these devices. The references selected here are far from being complete and fully exhaustive of the really numerous works published in the last years, but they rather are meant to highlight some specific important features and to furnish a representative scenario of the advances and progress in this field.

\section{PANI-based gas sensing. Electrical properties}

PANI chains, resulting from oxidative polymerization of aniline, are composed by two structural units, a reduced [B-NH-B-NH] and an oxidized [B$\mathrm{N}=\mathrm{Q}=\mathrm{N}^{-}$] repeat units, where $\mathrm{B}$ denotes benzenoid and $\mathrm{Q}$ denotes a quinoid ring. Quiniod ring and benzenoid can transform into each other by redox. The protonated PANI chain is electrically conductive only when $\mathrm{x}: \mathrm{y}=1: 1$ (i.e., benzenoid:quiniod=3:1) (Fig. 2).

Polyaniline has a reversible acid/base doping process. In acid or doped emeraldine salt form, polyaniline is conductive and, conversely, in the dedoped form or in emeraldine base form is insulating. 
The electrical conductivity of polyaniline increases with doping from the undoped insulating emeraldine base form $\left(\sigma<10^{-10} \mathrm{mho} / \mathrm{cm}\right)$ to the fully doped, conducting emeraldine salt form $(\sigma>1 \mathrm{mho} / \mathrm{cm})$ by modulating its oxidative state through changing counterions (dopant) and the degree of doping.

Dopants can be added in any desired quantity until all imine nitrogens (half of the total nitrogens) are doped, simply by controlling the $\mathrm{pH}$ of the dopant acid solution. Moreover, dopants can be removed by the interaction of the emeraldine salt form with common bases, such as ammonium hydroxide. The ability of switching between the conducting and insulating forms renders PANI polymer responsive to acid/base and reducing/oxidizing compounds such as ammonia $\left(\mathrm{NH}_{3}\right)$, nitrogen dioxide $\left(\mathrm{NO}_{2}\right)$, hydrogen $\left(\mathrm{H}_{2}\right)$ and some volatile organic compounds [36, 37, 38].

Electrical conductivity of this polymer depends on two different factors, i.e., the ability of the polymer backbone to transport charge carriers and the carriers hopping between different neighboring polymer chains. In the case of absence of any additives, the conduction mechanism is based on delocalized electron clouds and/or non-bonding electrons, which provides the conduction path in the polymer chains.

A panel that summarizes, as an example, the main electrical properties of polyaniline and polyaniline synthesized by doping with inorganic (hydrochloric acid $(\mathrm{HCl}))$ and organic ( \pm 10 -camphor sulfonic acid $(\mathrm{CSA}))$ acid is shown in Fig. 3. Data are taken from Ref. [39].

The frequency dependence electrical conductivity $\sigma(\omega)$ of this polymer follows a universal power law of the following form

$$
\sigma(\omega)=\sigma_{0}+a \omega^{s}
$$

where $\sigma_{0}$ is the d.c. electrical conductivity, $\omega$ the angular frequency of the applied electric field and $a$ and $s$ the prefactor and the exponent of the power law, respectively. The typical crossover from two different regions (d.c-a.c regions) can be easily evidenced in Fig. 3, as a change in the slope in a log-log plot. Results shown in Fig. 3 [39] clearly indicate that, in doped samples, additional electronic states with a reduction of inter-chain distances are formed, favoring the hopping of charge carriers, and resulting in a much higher electrical conductivity.

The dielectric properties of PANI base and doped PANI are shown in Fig. 3 where the data are presented through a Cole-Cole plot. The values 
of the zero-frequency and high-frequency limit permittivity confirm that, in doped PANI systems, two different mechanisms of polarization occur, a polaron/bipolaron mechanism, which allows mobile and free charges to move along the chain, and an orientational mechanism, where bound dipoles with restricted mobility account for the strong electrical polarization in the system.

These rather interesting electrical properties, together with the possibility of tuning their values by means of an appropriate doping process are essentially the reason by which polyaniline is widely used as selective layer in a chemical-vapor sensor, such as resistance type detectors (known as chemiresistors).

In order to increase its interactions with gas molecules, great effort has been payed in modifying the polymer backbone or in increasing interchain connections. The use of nanostructured polyaniline (such as nanowires, nanotubes, nanofibers, or nanorods) could greatly improve diffusion, favoring much greater penetration depth for gas molecules, relative to their bulk counterparts. PANI nanofibers were prepared by chemical polymerization of aniline by Huang and Kaner [40] and a facile route to polyaniline nanofibers (diameter between 30 and $50 \mathrm{~nm}$ with lengths varying from 500 to several micrometers) has been proposed by Huand et al. [33].

\section{Affinity of conducting polymers to gases. Kinetic and diffusion models}

Gases interacting with conducting polymers can be divided in two main classes: i) gases which chemically react with conducting polymers leading to modification of the polymer chemical structure and ii) gases which physically adsorb on conducting polymers.

As far as this second mechanism is concerned, a simple model of gas adsorption has been proposed many years ago by Lin et al. [41, 42] and Hwang et al. [43]. These models are based, to a first approximation, on a mechanism described by a Langmuir adsorption isotherm, according to kinetic equation

$$
A+<\text { site }>\stackrel{k_{r}}{\stackrel{k_{f}}{\longrightarrow}}<A>
$$

where $k_{f}$ and $k_{r}$ are the forward and backward reaction rates, respectively and $A$ is the analyte. In stationary condition, the concentration of site coverage $<A>$ due to adsorption is given by

$$
<A>=\frac{K_{m} C_{0}}{1+K_{m} C_{0}}
$$


where $K_{m}=k_{f} / k_{r}$ is the adsorption equilibrium constant and $C_{0}=A+<$ $A>$ is the total concentration of the analyte. If the overall resistance of the sensing element can be regarded as the paralleling of several pseudo monolayers, each of them composed by several resistors in series, each monolayer presents a resistance $R$ given by

$$
R=m<A>r_{1}+m(1-<A>) r_{0}
$$

where $r$ is the generic resistance of the site $\left(r_{0}\right.$ is the vacant site resistance and $r_{1}$ the occupied site resistance) and $m$ the number of active sites in the monolayer. Substitution of eq. 3 and eq. 4 results in the sensing response $\Delta R$ given by

$$
\Delta R=\left(r_{1}-r_{0}\right) \frac{m}{n} \frac{K_{m} C_{0}}{1+K_{m} C_{0}}
$$

where $n$, the number of monolayers, takes into account the whole thickness of the sensing element, i.e., the thin polymer film.

The characteristic parameters of the model can be easily obtained by plotting the reciprocal of $\Delta R$ against the reciprocal of the gas concentration $C_{0}$, resulting in a linear relationship where the value of $(m / n)\left(r_{1}-r_{0}\right)$ can be determined from the reciprocal of the intercept and $K_{m}$ can be obtained by dividing the intercept by the slope. The response $\Delta R$ essentially depends on the difference $\left(r_{1}-r_{0}\right)$ between the resistance of the vacant and occupied site and on the efficiency of the adsorption process through the equilibrium constant $K_{m}$.

A simple expression for the response $S$ of a polymer layer gas sensor has been derived by Sakai et al. [44]. If the adsorption process is still governed by a first-order kinetics (eq. 2), the diffusion equation can be written as

$$
\frac{\partial C}{\partial t}=D \frac{\partial^{2} C}{\partial x^{2}}-K_{m} C
$$

where $C$ is the concentration of the target gas, $D$ the diffusion coefficient and $x$ the distance from the top surface of the sensing layer. In the steady-state condition, with the boundary conditions $C=C_{0}$ at $x=0$ and $\partial C / \partial x=0$ at $x=L$, with $L$ the thickness of the sensing layer, the concentration $C$ is given by

$$
C(x)=C_{0} \frac{\cosh \sqrt{\frac{K_{m}}{D}}(L-x)}{\cosh \sqrt{\frac{K_{m}}{D} L}}
$$


On the further assumption that the conductance $\sigma(x)$ of the layer is linear with the concentration $C$

$$
\sigma(x)=\sigma_{0}(1+a C)
$$

and taking into account that the inverse of the resistances are given by

$$
\begin{aligned}
\frac{1}{R_{0}} & =\int_{0}^{L} \sigma_{0} d x \\
\frac{1}{R} & =\int_{0}^{L} \sigma(x) d x
\end{aligned}
$$

the response of the layer, defined as the ratio $S=R / R_{0}$ can be expressed as

$$
S=\frac{R}{R_{0}}=1+\frac{a C_{0}}{\sqrt{\frac{K_{m}}{D}} L} \tanh \left(\sqrt{\frac{K_{m}}{D}} L\right)
$$

The typical behavior of the sensitivity $S$ as a function of the adimensional parameter $m=L \sqrt{\frac{K_{m}}{D}}$ is shown in Fig. 4 .

A more elaborated analysis has been carried out, some years ago, by Bartlett and coworkers $[45,46]$ who analyzed the general problem of a gaseous species, A, diffusing into a homogeneous polymer film of thickness L, deposited across the gap between two thin electrodes on an impermeable substrate. If the gas adsorption process is again described by eq. 2, the overall process is governed by a modified diffusion equation that, in dimensionless spatial and temporal variables $\chi$ and $\tau$, assumes the form,

$$
\frac{\partial^{2} \gamma}{\partial \chi^{2}}-\frac{\partial \gamma}{\partial \tau}=\frac{\eta}{\lambda} \frac{\partial \theta}{\partial \tau}
$$

where $\chi=x / L$ is the normalized distance, $\tau=D t / L^{2}$ the normalized time, $C / C_{0}$ the normalized gas concentration, with $C_{0}$ the external gas concentration and, finally, $\eta=K_{m} N$ and $\lambda=K_{m} C_{0}$ constants depending on the material properties, i.e., the equilibrium constant $K_{m}$ and the density of the sites $N$.

The normalized concentration $\theta$ of the gas released on desorption from the diffusion process by sites can be related to the sorption kinetics by the equation

$$
\eta \frac{\partial \theta}{\partial \tau}=\nu \lambda \gamma(1-\theta)-\nu \theta
$$


where $\nu$ is a dimensionless parameter given by $\nu=k_{f} N L^{2} / D$.

Solution of eqs. 12 and 13 with suitable boundary conditions furnishes the profile of the adsorption and desorption concentration $\gamma(\chi, \tau)$ and $\theta(\chi, \tau$,$) ,$ respectively. These equations have been solved in a variety of different boundary conditions by Barlett et al. [45, 46] and some typical results are shown in Fig. 5. This model is particularly adaptable to the experimental results through the appropriate choice of its characterizing parameters.

Beside gas adsorption, another important effect that must be taken into consideration in the interpretation of the sensing response of conducting polymers to gases (particularly to organic vapors) is the swelling of the polymer film. Even if most conducting polymers are in their glassy state, swelling cannot be neglected $[47,48,49]$ since inserting analyte molecules into the polymer matrix increases interchain distance, modifying the electron hopping between different polymer chains and ultimately modifying the polymer conductivity.

This process has been recently modeled by Vercelli et al. [50] who describe the interchain electron transfer through the equation

$$
\left(\ln \frac{\sigma}{\sigma_{0}}\right)^{-1}=\frac{\epsilon_{p}}{B\left(\epsilon_{s}-\epsilon_{p}\right)} \frac{1}{X}+\frac{1}{B}
$$

where $\sigma$ and $\sigma_{0}$ are the electrical conductivity before and after exposed to solvent vapor, respectively, $\epsilon_{s}$ and $\epsilon_{p}$ are the permittivities of the solvent and the polymer, $X$ is the molar fraction of adsorbed vapor for sensing polymer and $B$ is a constant. This relationship is well accounted for in the case of n-hexane adsorbed in neutral poly $\left(\mathrm{N}, \mathrm{N}^{\prime}\right.$-dihexyldipyrrole) [50].

An adsorption model particularly suitable in the case of PANI structures as fibers has been developed recently by Zhang et al. [51]. This model is based on the idea that concentric shells on the fiber could form parallel conducting pathways through the length of the fiber itself, analogous, to a certain extent, to the kinetic model proposed by Lin et al. [41, 42] and by Huang et al. [43], so that observed changes in the resistance can be written as

$$
\frac{R}{R_{0}}=\frac{\sigma_{0} L^{2}}{2 \int_{0}^{L} \sigma(r) r d r}
$$

where $r$ is the radial position in the fiber, $L$ its radius, $\sigma_{0}$ the fiber conductivity prior to exposure and $\sigma(r)$ the radially varying conductivity, function of the concentration of the reactive component in the fiber. These authors 
[51] write a series of partial differential equations (eqs. 3-6 in ref. [51]) whose numerical solution depends essentially on two parameters, the dimensionless time $\tau=t D / L^{2}$, where $D$ is the diffusion coefficient of the gas, and $D_{a}$, the Danköheler number defined as $D_{a}=k_{f} C_{0} \theta L^{2} / D$, where $k_{f}$ is the forward reaction rate constant and $\theta$ is the normalized concentration of the diffusing gaseous reactant. Typical example of the resistive response is shown in Fig. 6 , where the change in the resistance $R / R_{0}$ is given as a function of the reduced time $\tau$ and of the Danköheler constant $D_{a}$. If the constant $D_{a}$ is large, reaction predominates over diffusion and the diffusion profile penetrates slowly into the fiber. Conversely, if $D_{a}$ is small, diffusion is much faster than reaction and the gas penetrates rapidly the entire fiber. This model is particularly suitable to extract physical parameters from fitting experimental data.

\section{PANI-based gas and vapour sensors}

In this section, we will report and comment some of the most interesting applications of PANI polymers as gas sensors developed in the most recent years. Due the extremely varied morphological structures of the nanocomposite materials, we have preferred avoiding any partition in different subgroups and the examples we have selected will be discussed without any predefinite order.

A sensitive and selective chemiresistive sensor for $\mathrm{H}_{2} \mathrm{~S}$ detection at room temperature has been recently described by Shirsat et al. [52]. This sensor consists of polyaniline nanowires electrochemically functionalized with gold nanoparticles, using cyclic voltammetry technique. In this case the main problem is that $\mathrm{H}_{2} \mathrm{~S}$ is a weak acid and therefore does not interact significantly with PANI and does not change its electrical conductivity significantly. However, when PANI nanowire network was functionalized with gold nanoparticles $(70-120 \mathrm{~nm}$ in size) by electrodeposition, the hybrid sensor showed an excellent response even at concentration as low as $0.1 \mathrm{ppb}$, with a dynamic range from 0.1 to $100 \mathrm{ppb}$ and a very good selectivity and reproducibility. Fig. 7 shows the normalized change in resistance $\Delta R / R_{0}$ of gold nanoparticles decorated PANI nanowires network, where $R$ and $R_{0}$ are the resistances in analyte gas and air, respectively, as a function of time. As can be seen, nanoparticle functionalization produces enhanced sensitivity accompanied by a linear response. 
Polyaniline nanofibers as sensing materials have been prepared by Virji et al. [34], who monitored their time response when exposed to $\mathrm{HCl}, \mathrm{NH}_{3}$, $\mathrm{N}_{2} \mathrm{H}_{4}, \mathrm{CHCL}_{3}$ and $\mathrm{CH}_{3} \mathrm{OH}$, evidencing five different mechanisms (acid doping in the case of hydrochloric acid, base dedoping for ammonia, reduction in the presence of hydrazine, swelling in the presence of chloroform and, finally, a change in the conformation of the polymer chain in the presence of methanol). These results clearly demonstrate the great flexibility of the system and, at least in part, justify the wide use of these materials as gas sensors. Interestingly, the authors find that both the response time and the extent of the response is significantly better for polyaniline nanofiber than in the case of polyaniline film produced in a conventional way. Fig. 8 presents a panel where the typical responses are collected together.

Nanostructured PANI films were prepared from polystyrene [PS]-PANI coreshell particles by Yang and Liau [53] who investigated the responses of the resulting nanostructured films to different dry gas flow, ethanol vapor, hydrogen chloride, and ammonia. The influence of the specific area and porosity associated with these structures was examined in two different cases. In the first one, (referred to as $\mathrm{P}$ films), the nanostructures resulting after removal of PS cores by immersing the coreshell particles dried on a substrate into THF, were composed of irregular fragments of PANI shells of tens of nanometers. In the second case, the coreshell particles became PS-PANI composite films (referred to as $\mathrm{F}$ films) after heating at $140{ }^{\circ} \mathrm{C}$ for $10 \mathrm{~min}$, and the nanostructures were obtained by THF extraction of PS.

The effect of ethanol vapor on the resistance of two nanostructured PANI films is shown in Fig. 9. As noted by these authors [53], it was not easy to distinguish the two kinds of nanostructured films from SEM micrographs (inset in Fig. 9), but the conductivity response behaviors were clearly different (as shown in Fig. 9).

This different behavior is due to the fact that ethanol does not change the oxidation state or the doping level of PANI and thus has little effect on the conductivity of PANI itself. However, ethanol may swell the PANI backbones causing an increase in its resistance.

PANI doped with camphor sulphonic acid [CSA] showed a good response to alcohol vapors [54]. PANI and its substituted derivatives such as poly(otoluidine), poly(o-anisidine), poly(N-methyl aniline), poly(N-ethyl aniline) and poly(diphenyl amine) were found sensitive to methanol, ethanol. propanol, buthanol and hepatanol vapors by undergoing a change in the electrical resistance [55]. In particular, resistance decreases in the presence of small chain 
alcohols but with an opposite trend in the case of long chain alcohols.

Kaner and Fowler $[38,56]$ demonstrated that hydrogen interacts directly with doped PANI nanofibers to induce a small change in the conductivity of the nanofibers. The direct mass uptake of hydrogen by PANI nanofibers was also observed using a quartz crystal microbalance (ca. 3\% relative to the nanofiber mass). A plausible mechanism of the hydrogen/PANI interaction involves hydrogen interacting with doped PANI at the charged amine nitrogen sites, followed by the dissociation of hydrogen with the formation of new NH bonds at the amine nitrogen of the PANI chain. Subsequently, charge transfer between adjacent amine nitrogens returns the PANI back to its original doped, emeraldine-salt form with a release of hydrogen.

A hybrid material particularly suitable for $\mathrm{NH}_{3}$ recognition based on nanostructured polyaniline and titanium dioxide $\left[\mathrm{PANi}-\mathrm{TiO}_{2}\right]$ has been recently proposed and characterized by morphological analysis by Pawar et al [57]. The response at room temperature of different oxiding and reducing gases of $\mathrm{PANi}^{-\mathrm{TiO}_{2}}$ film is shown in Fig. 10. The high sensitivity for $\mathrm{NH}_{3}$ in comparison with other gases investigated $\left(\mathrm{CH}_{3} \mathrm{OH}, \mathrm{C}_{2} \mathrm{H}_{5} \mathrm{OH}, \mathrm{NO}_{2}\right.$, $\mathrm{H}_{2} \mathrm{~S}$ ), has been attributed by the authors to its high electron affinity values in comparison with other gases.

Sensors based on titanium dioxide $\left(\mathrm{TiO}_{2}\right)$ used for the detection of $\mathrm{H}_{2}$, $\mathrm{NH}_{3}, \mathrm{NO}_{2}$ gases require an elevated temperature [58, 59] or platinum doping [60]. This disadvantage can be overcome by preparing a polyaniline-titanium dioxide [PANI $/ \mathrm{TiO}_{2}$ ] nanocomposite thin film. Tai et al. [61] report the gas response of $\mathrm{PANI} / \mathrm{TiO}_{2}$ thin film to $\mathrm{NO}_{3}$ and $\mathrm{CO}$ gases at room temperature with gas concentration between 10 and $150 \mathrm{ppm}$. The main results concerning $\mathrm{NH}_{3}$ sensing behaviour are shown in Fig. 11. This is a clear example of how the composite material displays a much better performance when compared with the one of pure PANI. In this case, sensor exhibits fast response, short recovery time and high sensitivity. Moreover, the sensor is preferred to be operated at room temperature (see inset of Fig. 11).

Sharma et al. [62] demonstrated the applicability of $\mathrm{Cu}$-polyaniline [CuPANI] as a sensing element for chlorinated hydrocarbons (in particular as chloroform sensor). Copper nanoclusters associated with the polymer film structure of $\mathrm{Cu}-\mathrm{PANI}$ nanocomposite favor adsorption of gas on the metal surface, making them ideal microsensors. Typical response presented as $\Delta R / R$, where $\Delta R$ is the resistance on gas exposure and $R$ is the initial value of the sensing pellet is shown in Fig. 12, for various chloroform concentrations. 
An extended analysis of the results on the PANI nanofiber sensors to various concentrations of aromatic organic compounds [AOC] has been recently carried out by $\mathrm{Li}$ et al. [63]. Investigations include benzene, toluene, xylene, p-xylene, m-xylene, o-xylene, chlorobenzene, ethylbenzene. Since these compounds are of liquid form at room temperature, a bubbler evaporation system was employed to deliver the controlled concentrations of the volatile analytes to the sensors. In Fig. 13, the resistance change of the polyaniline films upon exposure to different vapors are shown.

A polyaniline (PANI)/ $\mathrm{SnO}_{2}$ hybrid material was prepared by Geng et al. [64] and employed for gas sensing of ethanol and acetone. In this case, the competitive mechanism of the electronic properties in the hybrid material (PANI is a p-type semiconductor and $\mathrm{SnO}_{2}$ is a n-type semiconductor) favors its n-type character and consequently the resistance decreases when exposed to the reducing gases. While the sensor is ineffective to ethanol and acetone at $30{ }^{\circ} \mathrm{C}$, it becomes sensitive to these vapors when operated at 60 and 90 ${ }^{\circ} \mathrm{C}$, with an acceptable recovery time, of the order of some tens of seconds.

Conducting polymer-Au composite materials can be utilized for chemical sensing, for example in the amperometric sensing of $\mathrm{NO}_{2}$. In particular, the sensitivity of PANI/Au/Nafion composite is relatively high, of the order of 2 $\mathrm{mA} / \mathrm{ppm}$ for $\mathrm{NO}_{2}$. In this case, it deserves to be noted that gold is deposited on Nafion and the polyaniline is electrochemically grown on the Nafion/Au substrate forming a Nafion/Au/PANI sandwich structure with a sensitivity increased in comparison with the $\mathrm{Au} / \mathrm{Nafion}$ sensor [65].

By varying the chemical synthesis, the morphological structure of PANI can be easily controlled and PANI nanotubes, PANI nanofibers and PANI nanowires have been synthesized by different groups [33, 53, 66]. This possibility opens the question whether or not the morphology of PANI could influence its performance as a chemiresistive sensor.

Briseno et al. [67] have investigated three different PANI structures for the detection of n-butylamine vapors. They employed 2-napthalenesulfonic acid-doped PANI structures as nanofibers and nanotubes and compared the resistance response with the one of commercially available PANI. In this case, authors found that the three differently structured materials behave similarly, at least up to butylamine vapor concentration of the order of 500 ppm, with a slightly better performance of commercially available PANI at the higher concentrations.

Nanofibers of PANI decorated with highly dispersed gold nanoparticles [AuNPs] have been recently developed by Lin et al. [68] in order to detect 
volatile sulfur compounds of human expired breath. Sensors realized by a redox reaction between $\mathrm{HAuCl}_{4}$ and PANI in form of emeraldine exhibit a good response to $\mathrm{H}_{2} \mathrm{~S}$ and $\mathrm{CH}_{3} \mathrm{SH}$ gases. Interestingly, these sensors have been employed to detect volatile sulfur compounds [CSCs] contained in human breath. These results are collected together in Fig. 14, where the real time response of PANI/AuNP sensors are presented. The response of the sensor to the expired breath of a healthy volunteer after ingesting raw garlic opens the possibility of employing this device in disease diagnose related to biomarker gases.

Nanostructured composite materials based on polyaniline (PANI) and gold nanoparticles have been prepared by Venditti et al. [69] through an osmosis based method. This nanocomposite has been exposed to different vapor organic compounds (VOCs) of interest in the fields of environmental monitoring and biomedical applications, such as toluene, acetic acid, ethanol, methanol, acetonitrile and its behavior has been compared with the one in the absence of gold nanoparticles. The results are summarized in Fig. 15 for both nanoPANI and nanoPANIAu samples. In particular, nanoPANIAu showed sensitivity to ammonia (up to $10 \mathrm{ppm}$ ) higher than that to other VOCs or interfering analytes.

Zhang et al. [51], to overcome the difficulty of processing PANI into fibers, have recently reported the successful production of continuous fibers of PANI doped with + camphor-10-sulfonic acid [HCSA], by coaxial electrospinning with subsequent removal of the shell polymer. The system behaves as a nanoscale sensor for both ammonia $\left(\mathrm{NH}_{3}\right)$ and nitrogen dioxide $\left(\mathrm{NO}_{2}\right)$ gases, exhibiting in both cases a high sensitivity and a fast response time.

However, the resistive response for the two gases is rather different, being up to six order of magnitude for $\mathrm{NO}_{2}$ and less than two order of magnitude for $\mathrm{NH}_{3}$. The two reaction equilibrium equations could be

$$
P A N I-H^{+}+\mathrm{NH}_{3} \rightleftarrows P A N I+\mathrm{NH}_{4}^{+}
$$

with

$$
\frac{[P A N I]}{\left[P A N I-H^{+}\right]} \simeq 1
$$

and

$$
\mathrm{PANI}-\mathrm{H}+\mathrm{NO}_{2} \rightleftarrows \mathrm{PANI}+\mathrm{HNO}_{2}
$$

with

$$
\frac{[P A N I]}{[P A N I-H]} \rightarrow \infty
$$


changing, in this second case, PANI from its undoped insulating state to almost the fully doped, high conductivity state [51]. This example evidences how electrospun PANI fibers, because of the easiness with which PANI is doped or dedoped, show an exceptional gas sensing performance for reducing and oxidizing gases as $\mathrm{NH}_{3}$ and $\mathrm{NO}_{2}$.

The deprotonation of PANI by $\mathrm{NH}_{3}$ has been also confirmed by Lim et al. [70] who investigated the sensing properties of single-walled carbon nanotube networks functionalized with polyaniline [PANI-SWCNs] in the presence of $\mathrm{NH}_{3}, \mathrm{NO}_{2}$ and $\mathrm{H}_{2} \mathrm{~S}$ gases.

While in the case of unfunctionalized SWCN sensors there is a charge transfer between electron donating molecules and SWNT, for PANI-SWNT network sensors, adsorbed $\mathrm{NH}_{3}$ molecules deprotonate $N^{+}-H$ sites of polyaniline (emeraldine salt), causing significative conductance change.

The typical real-time response of PANI-SWNT sensors to different concentrations of $\mathrm{NH}_{3}, \mathrm{NO}_{2}$ and $\mathrm{H}_{2} \mathrm{~S}$ at room temperature are shown in Fig. 16. These authors reported that the electrical resistance drastically increases upon exposure to $\mathrm{NH}_{3}$ with a sensor response time that decreases from 75 min at $50 \mathrm{ppm}$ to $1 \mathrm{~min}$ at $100 \mathrm{ppm}$, with recovery time ranging from several minutes to few hours. In the case of exposure to $\mathrm{NO}_{2}$, the resistance decreased consistently with the transfer of $\pi$ electrons from PANI to the adsorbed $\mathrm{NO}_{2}$, resulting in a positive charge for PANI. A similar behavior is observed in the presence of $\mathrm{H}_{2} \mathrm{~S}$ whose dissociation results in a partial protonation of PANI.

In the case of PANI, in order to increase the hydrophilicity of the nanofibers to facilitate their interaction with water, and thus to obtain a sensitive humidity sensor, Lin et al. [71] employed electrospinning technique from the blend of PANI-poly(styrene sulfonic acid) (PSSA), poly(vinyl butynol) (PVB) and polyethylene oxide (PEO). The introduction of PEO into the electrospinning solution modifies the hydrophylicity of the PANI nanofibers, increasing the response to humidity, with high sensitivity, fast response and small hysteresis. All the nanofiber sensor investigated showed impedance (resistance) change of about three order of magnitude over the range $20 \%$ to $90 \% \mathrm{RH}$ with high sensitivity. For example, the transient response of PANI-PSSA/PEO/PVB (mass ratio 20/3/14) evidences a fast response with a response time $t_{90 \%}$ for adsorption and desorption processes of the order of $8 \mathrm{~s}$ and $6 \mathrm{~s}$, respectively.

Srinives et al. [72] fabricated a PANI nano-thin film chemiresistor sensor using a potentiostatic techniques on a n-octadecyltrichlorosilane [OTS] pretreated microelectrode. The sensing performance of these films was tested by 
exposing them to $\mathrm{NH}_{3}$ and $\mathrm{NO}_{2}$ gases with encouraging results (sensitivity $21 \% / \mathrm{ppm}$ for $\mathrm{NH}_{3}$ and $3760 \% / \mathrm{ppm}$ for $\mathrm{NO}_{2}$ ) and good reproducibility. Here, sensitivity is defined as the slope of the linear range of the calibration curve.

Adsorption of $\mathrm{NH}_{3}$ on PANI induced $\mathrm{NH}_{4}^{+}$formation and resulted in dedoping of emeraldine salt to emeraldine base decreasing the conductivity of the sensor. Sensor sensitivity is about $21 \% / \mathrm{ppm}$ and the limit of detection [LOD], defined as 3 times standard deviation of the blank sample divided by the slope of the linear part of the calibration curve,was about $35 \mathrm{ppm}$.

In the case of $\mathrm{NO}_{2}$ gas, the possible mechanisms of interaction are either a partial doping of PANI emeraldine base [73] or oxidization of PANI emeraldine salt [37], but results validate that $\mathrm{NO}_{2}$ acts as an oxidizing agent converting PANI emeraldine salt to its higher oxidation state. In this case, sensitivity is about $3700 \% / \mathrm{ppm}$ and LOD about $0.6 \mathrm{ppb}$. In both cases, reproducibility is very high, better than $2 \%$.

PANI/Ag films (with $\mathrm{AgNO}_{3}$ concentration around 0.5 M) were prepared by Mekki et al. [74] and their chemiresistive gas sensing properties were investigated by exposure of $10 \mathrm{ppm}$ of different gases, but appropriate response wes observed only for $\mathrm{H}_{2} \mathrm{~S}$ gas. Authors observed an increase of the electrical current upon gas exposure instead of an expected decrease, considering the electron donating nature of $\mathrm{H}_{2} \mathrm{~S}$ (reducing gas). The justification of this effect lies in the dissociation of $\mathrm{H}_{2} \mathrm{~S}$ on the metal surface, resulting in $\mathrm{H}^{+}$and $\mathrm{HS}^{-}$ions. While the anion compensates the $\mathrm{N}^{+}$charge in the PANI chain, $\mathrm{H}^{+}$, whose mobility is much larger than the anion, imparts the observed conductivity. Further evidence to this mechanism derives from the fact that, in the presence of Ag clusters, the effective PANI matrix, which governs the conductivity change on $\mathrm{H}_{2} \mathrm{~S}$ exposure, is greatly reduced. These characteristics, such as detection limit at $1 \mathrm{ppm}$ and the fast response time, makes this composite a good candidate for $\mathrm{H}_{2} \mathrm{~S}$ gas sensing.

In order to overcome the relatively high resistivity displayed by the conventionally doped PANI, that might cause difficulty on gas sensing measurements, Wanna et al. [75] used a PANI/carbon nanotubes [CNT] composite sensor operating at room temperature for $\mathrm{CO}$ sensing. The inclusion of CNT in PANI had the effect of considerably improving the sensor characteristics, achieving good sensitivity, fast response and low concentration detection.

An improvement of the performance of PANI-based gas sensors was recently obtained by Qi et al. [76] by means of in situ fabrication of PANI coating onto porous non-woven fabrics. Response to various volatile organic compounds are shown in Fig. 17. 
Finally, some of the results discussed here together with some others from the recent literature are collected in Tab. 1, where the different analytes, together with the morphology and the main characteristics and performances, as far as sensitivity, detection limit and operation range are reported. As can be seen, these structures represent a powerful detection platform with a number of key features, in particular, the possibility of using nanostructured PANI to efficiently detect various types of gases and some organic vapours.

\section{Conclusions}

Among conducting polymers, polyaniline [PANI] has captured wide interest due to the discovery of its high electrical conductivity, beside its optical and electro-optical properties. PANI-based sensors, which transform a chemical interaction into an electrical signal, covering a broad spectrum of applications, have successfully been demonstrated as efficient sensors for monitoring organic and inorganic compounds, such as alcohols, esthers, ammonia, nitrogen, $(\mathrm{NO})_{x}, \mathrm{H}_{2} \mathrm{~S}, \mathrm{SO}_{2}, \mathrm{CO}_{2}$. In this review, we have collected and discussed a series of rather recent works that, far from being an exhaustive coverage of all published works, illustrate the quite important progresses reached in this field, evidencing how the structural versatility of these polymers makes them ideal candidates for use as sensitive chemical sensors, with additional advantages of a high selectivity, a fast response and recovery time. This has become possible only because polyaniline may be tailored for particular properties. The possibility of adding functional guests into the polymer matrix greatly broadens the use of PANI sensors. The examples we have selected here illustrate how, based on the facile preparation and the properties they posses beside easy device fabrication and room-temperature operation, polyaniline-based gas sensors have promise for applications in different contexts such as industrial emission control, household security, vehicle emission control and environmental monitoring and biosensors. 


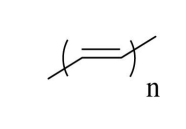

polyacetylene

(PA)

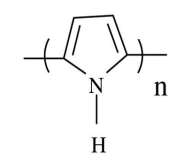

polypyrrole

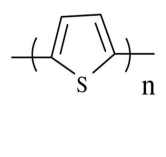

polythiophene

(PT)

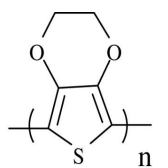

poly(3,4-ethylene dioxythiophene)

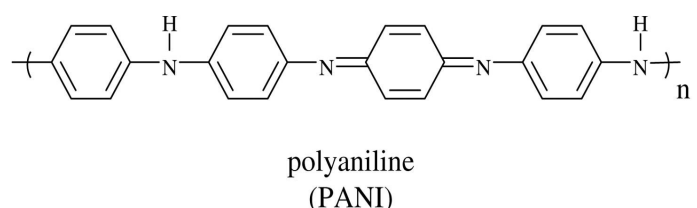

(PANI)

Figure 1: Chemical structures of some typical conducting polymers. Reproduced with permission from Ref. [77]

\section{Figures}



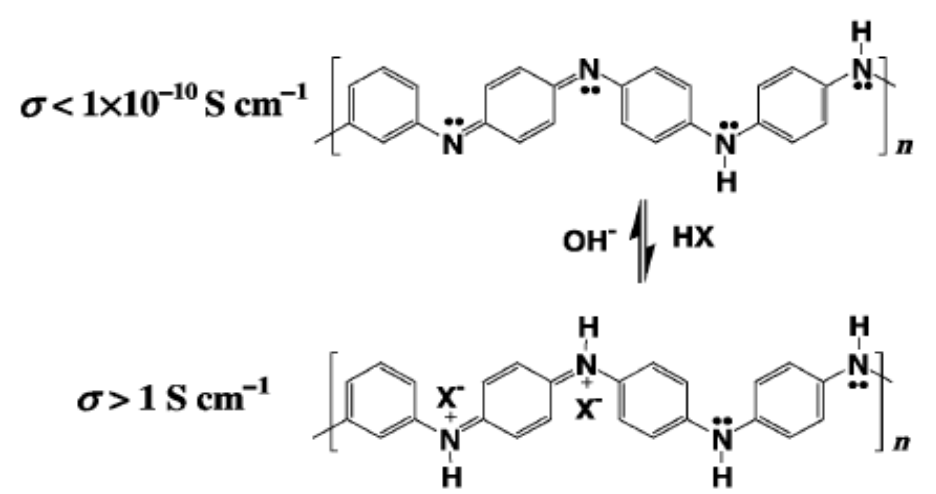

Figure 2: Repeat unit of the emeraldine oxidation state of polyaniline in the undoped, base form (top) and the fully doped, acid form (bottom). Doping can be carried out with any strong acid, HX, where X serves as the counterion to maintain charge balance. Dedoping can be accomplished with any strong base, $\mathrm{OH}^{-}$. Reproduced with permission from Ref. [33] 

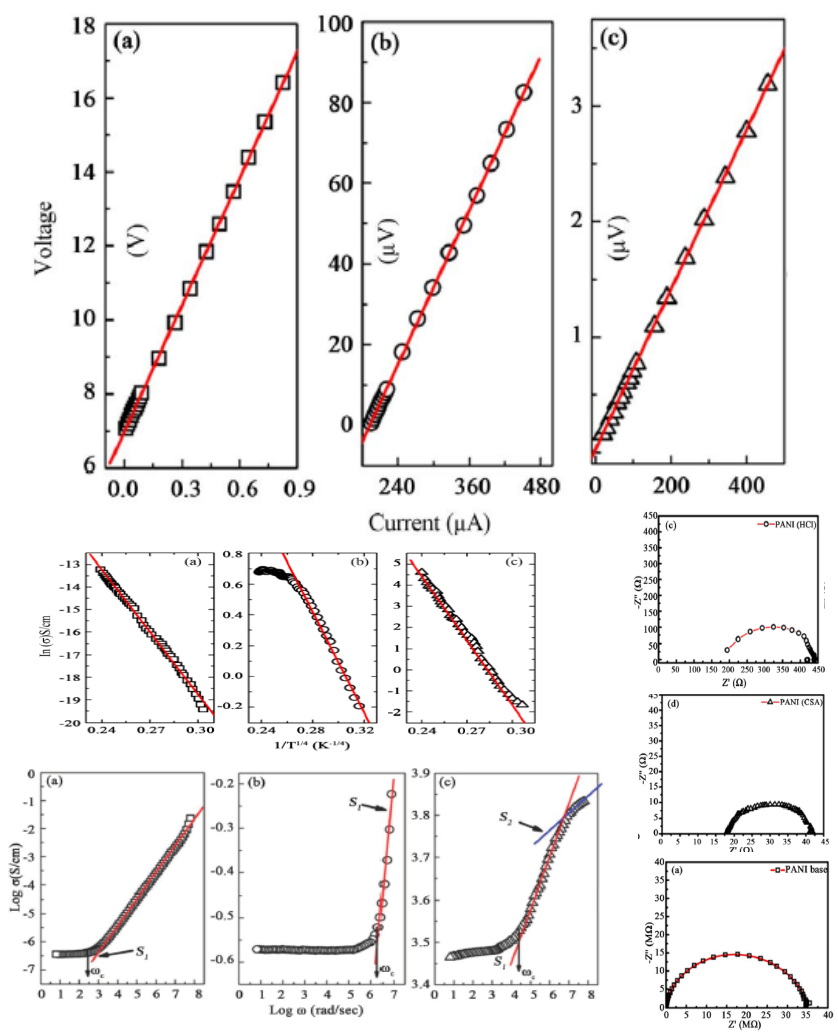

Figure 3: Upper panels: Current-Voltage characteristics of (a) PANI base, (b) PANI (HCl) and (c) PANI (CSA). Intermediate panels: Arrhenius plots for (a) PANI base, (b) PANI $(\mathrm{HCl})$ and (c) PANI (CSA). Bottom panels: Frequency dependent electrical conductivity $\sigma(\omega)$ for (a) PANI base, (b) $\mathrm{HCl}$ and (c) CSA doped PANI. $\omega_{c}$ indicates the DC-AC transition. On the right, Nyquist plot of (a) PANI base, (b) PANI ( $\mathrm{HCl}$ ) and (c) PANI (CSA). Reproduced with permission from Ref. [39] 


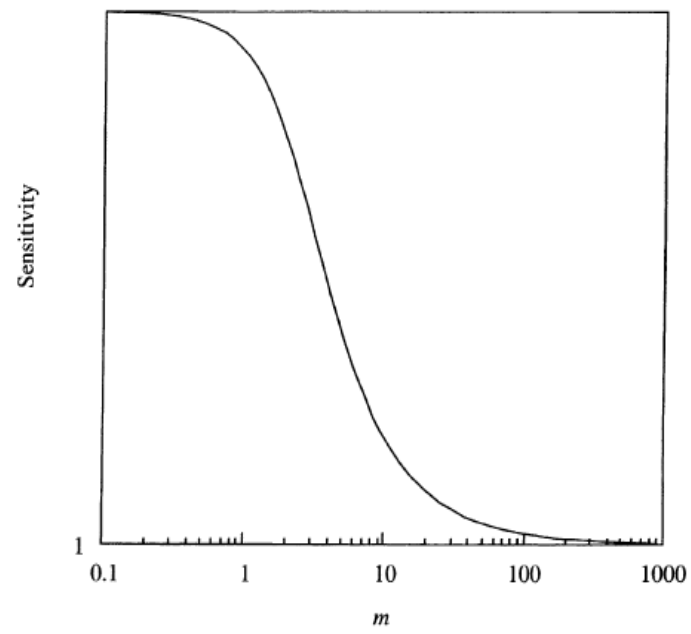

Figure 4: Generalized expression of the gas sensitivity of thin film in terms of the adimenional parameter $m=L \sqrt{\frac{K_{m}}{D}}$. Reproduced with permission from Ref. [44] 

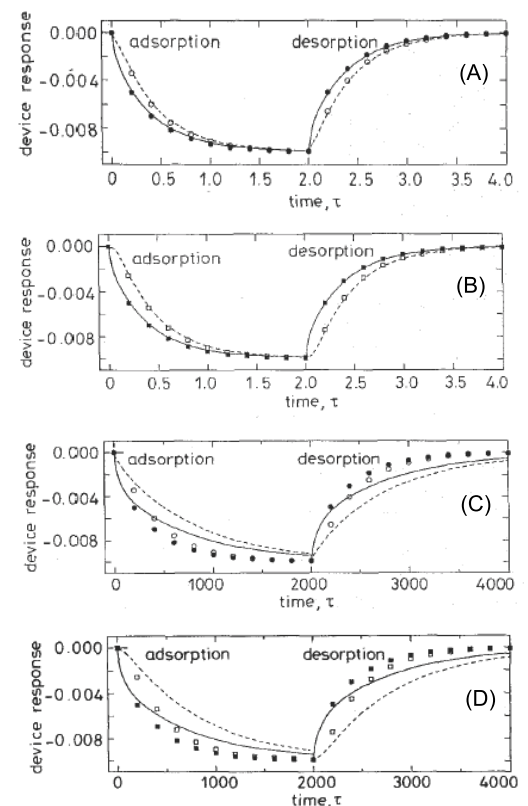

Figure 5: Theoretical responses of polymer devices for case $\lambda<1, \eta<1, \nu>\eta$ with semiinfinite electrodes (A) and with finite electrodes (B) and for case $\lambda<1, \eta<1$, $\nu>1$ with semiinfinite electrodes (C) and with finite electrodes (D). The lines show the numerical solutions and the symbols show the approximate analytical solution. The solid line and filled symbols are for $x / L=10$, and the dotted line and unfilled symbols are for $x / L=0.1$. Reproduced with permission from Ref. [45] 


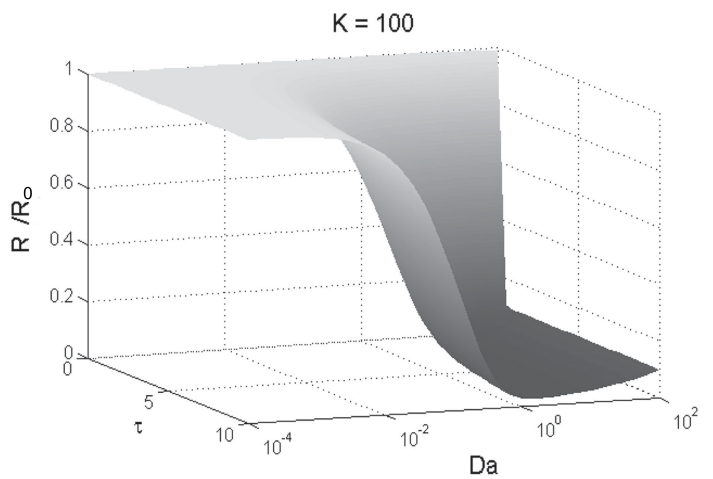

Figure 6: Results of the reaction-diffusion model showing the ratio $R / R_{0}$ of the resistance prior and after the exposure plotted as a function of the Damköhler constant $D_{a}$ and the dimensionless time $\tau$ for a selected value of the equilibrium constant $K=k_{f} / k_{r}(K=100)$. Reproduced with permission from Ref. [51] 


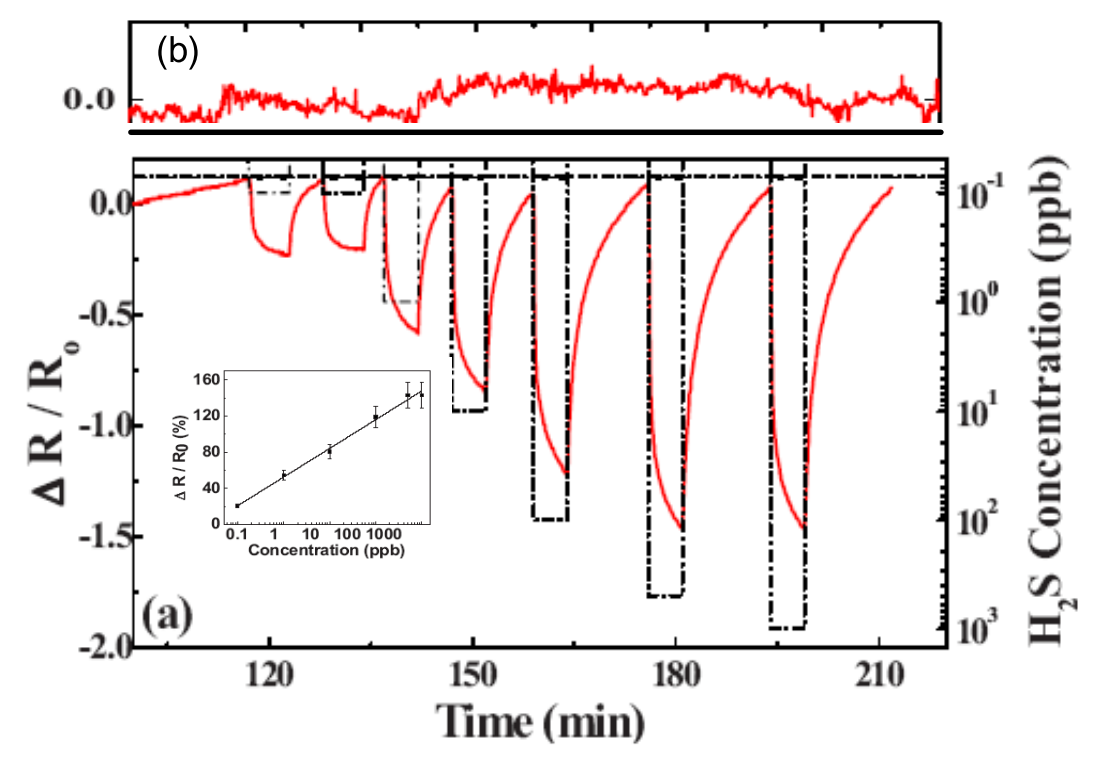

Figure 7: (a): Transient response $\Delta R / R_{0}$ of gold nanoparticle functionalized PANI nanowire network based chemiresistive sensors towards $0.1,1,10,100,500$ and $1 \mathrm{ppb}$ concentration of $\mathrm{H}_{2} \mathrm{~S}$ gas. The inset shows the response $\Delta R / R_{0}$ as a function $\mathrm{H}_{2} \mathrm{~S}$ concentration. (b): response of unfuncionalized PANI nanowire network towards $50 \mathrm{ppb}$ of $\mathrm{H}_{2} \mathrm{~S}$ gas. Reproduced with permission from Ref. [52] 

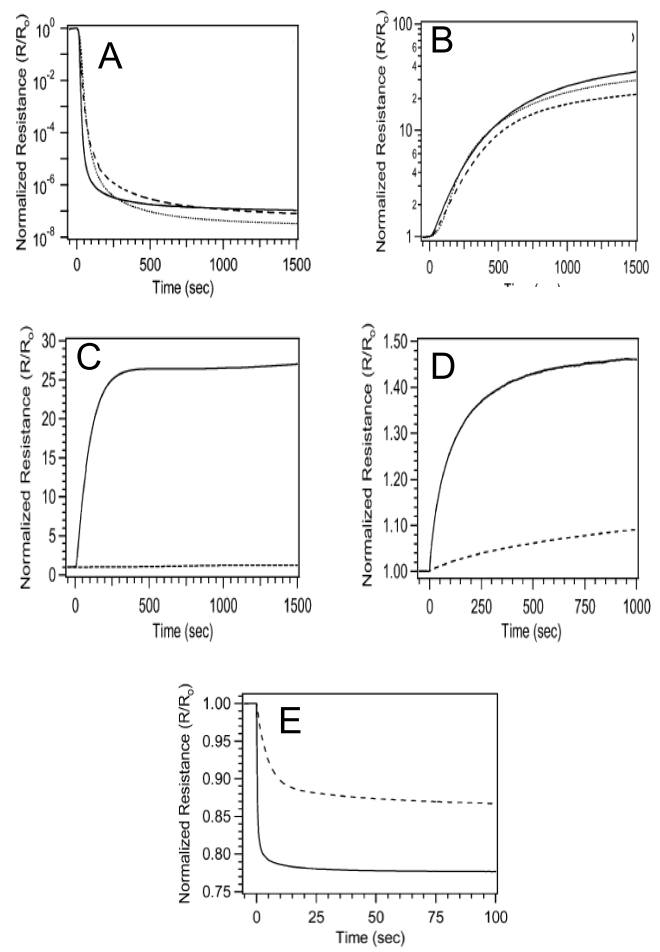

Figure 8: Response of polyaniline nanofiber to $100 \mathrm{ppm}$ gaseous $\mathrm{HCl}(\mathrm{A})$ and response to $100 \mathrm{ppm}$ gaseous $\mathrm{NH}_{3}$ (B). Fiber thickness: (full line): $0.2 \mu \mathrm{m}$; (dash line): $0.4 \mu \mathrm{m}$; (dotted line): $2.0 \mu \mathrm{m}$. Response of $0.3 \mu \mathrm{m}$ nanofiber (full line) and conventional polyaniline (dash line) thin films to $3 \mathrm{ppm}$ of hydrazin $(\mathrm{C})$ and response of $0.3 \mu \mathrm{m}$ nanofiber (full lne) and conventional polyaniline (dash line) thin films to $30000 \mathrm{ppm}$ of chloroform (D). Response of $0.3 \mu \mathrm{m}$ nanofiber (full line) and conventional polyaniline (dash line) thin films to 20000 ppm methanol (E). Redrawn with permission from Ref. [34] 


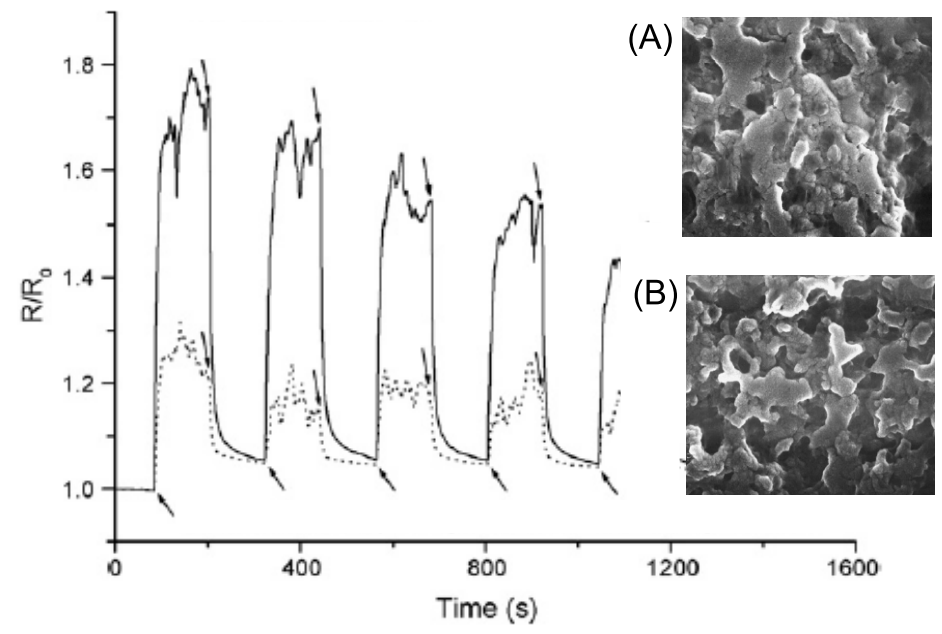

Figure 9: The effect of ethanol vapor on the resistance of $\mathrm{P}$ film (full line) and $\mathrm{F}$ film (dotted line). Redrawn and adapted with permission from Ref. [53] 


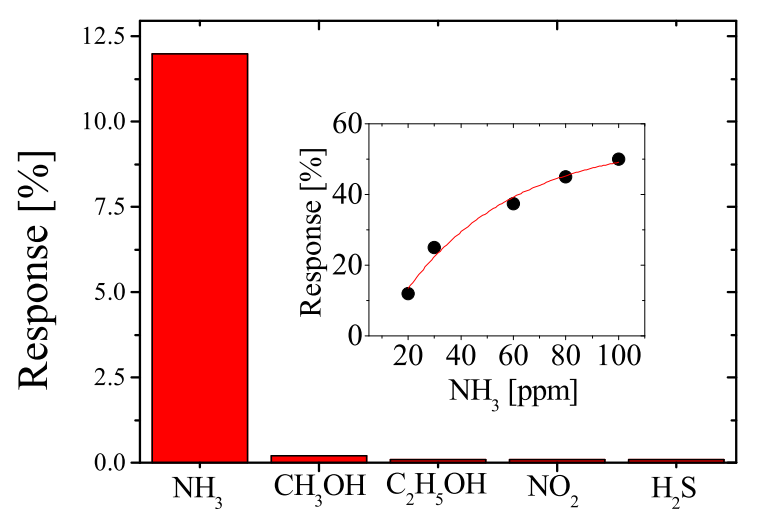

Figure 10: Response of PANI- $\mathrm{TiO}_{2}$ sensor film to $\mathrm{NH}_{3}$ (concentration $20 \mathrm{ppm}$ ), $\mathrm{CH}_{3} \mathrm{OH}$ (concentration $100 \mathrm{ppm}$ ), $\mathrm{C}_{2} \mathrm{H}_{5} \mathrm{OH}$ (concentration $100 \mathrm{ppm}$ ), $\mathrm{NO}_{2}$ (concentration 100 ppm), $\mathrm{H}_{2} \mathrm{~S}$ (concentration $100 \mathrm{ppm}$ ). The inset shows the response of the sensor to $\mathrm{NH}_{3}$ as a function of concentration in the range 20-100 ppm. Redrawn and adapted with permission from Ref. [57] 

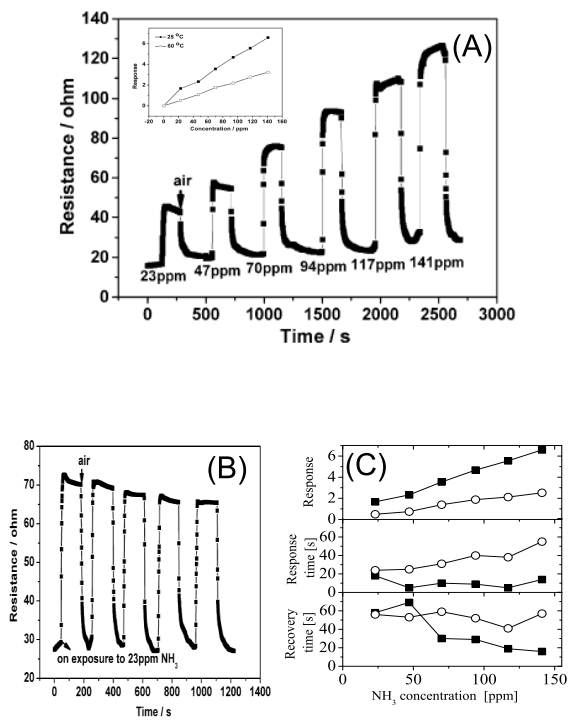

Figure 11: Upper panel: transient response of $\mathrm{PANI} / \mathrm{TiO}_{2}$ thin film sensor to $\mathrm{NH}_{3}$ at different concentration at the temperature of $25^{\circ} \mathrm{C}$. The inset shows a comparison between response at 25 and $60{ }^{\circ} \mathrm{C}$. Bottom panels, on the left: reproducibility of $\mathrm{PANI} / \mathrm{TiO}_{2}$ sensor exposed to $23 \mathrm{ppm} \mathrm{NH} 3$ at $25{ }^{\circ} \mathrm{C}$. Bottom panel on the right: Response $S=\left(R-R_{0}\right) / R_{0}$ upper, response time intermediate and recovery time bottom of $\mathrm{PANI} / \mathrm{TiO}_{2}$ film to various $\mathrm{NH}_{3}$ concentrations. Redrawn and adapted with permission from Ref. [61] 


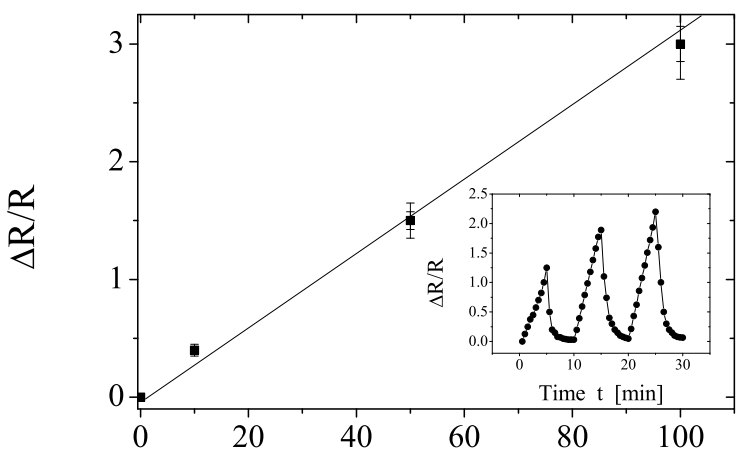

Chloroform concentration [ppm]

Figure 12: The maximum of the response of $\mathrm{Cu}$-PANI to exposure of chloroform at various concentrations (from 0 to $100 \mathrm{ppm}$ ). The inset shoes the temporal response Sensor was exposed to chloroform vapors for $5 \mathrm{~min}$ and to dry air for $5 \mathrm{~min}$, alternately. Redrawn and adapted with permission from Ref. [62] 

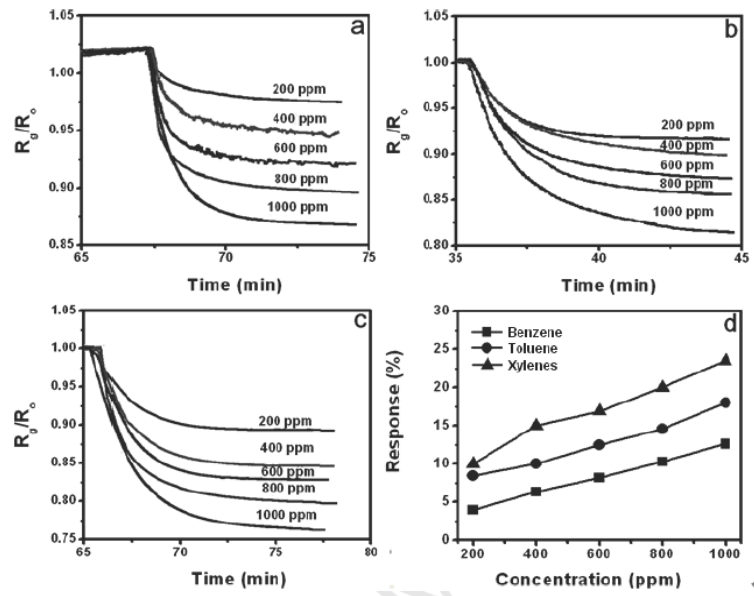

Figure 13: Resistance changes of polyaniline films upon exposure to different vapors in the range 200-1000 ppm: (a): benzene; (b): toluene; (c): xylene (d): linearity of the sensor response with the increase of vapor concentrations. Redrawn and adapted with permission from Ref. [63] 

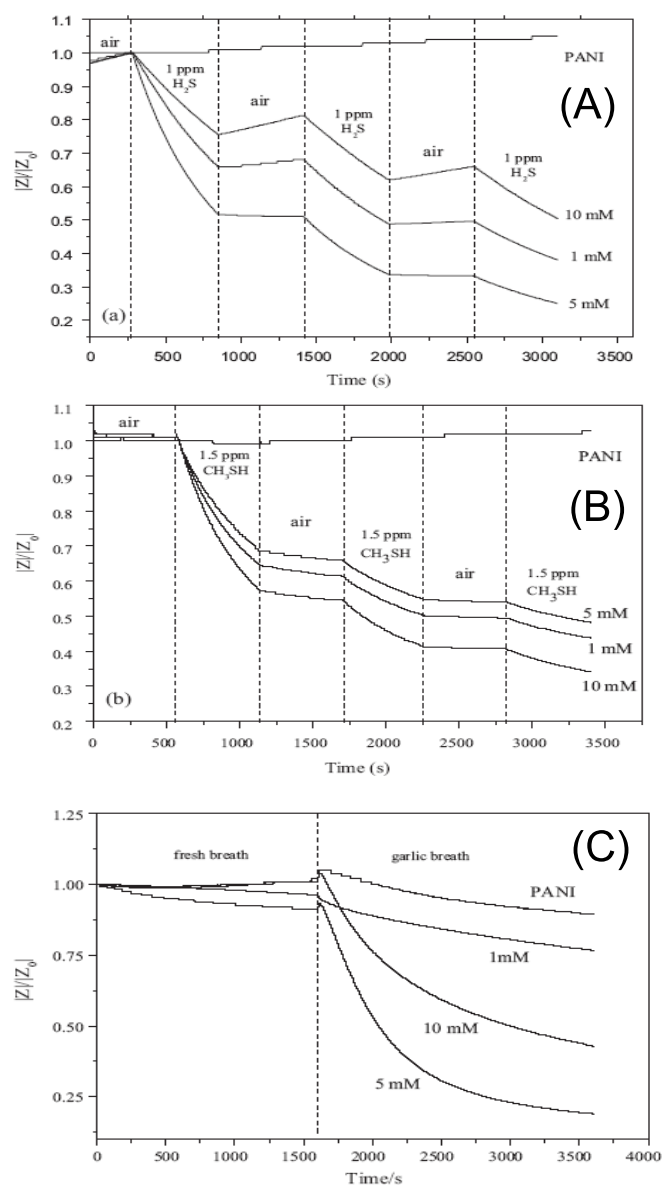

Figure 14: Real time impedance $Z / Z_{0}$ response of PANI/AuNPs sensors prepared with $1,5,10 \mathrm{mM} \mathrm{HAuCl}_{4}$ concentration upon exposure to $\mathrm{H}_{2} \mathrm{~S}(1 \mathrm{ppm})(\mathrm{A})$ and $\mathrm{CH}_{3} \mathrm{SH}(1.5$ $\mathrm{ppm}$ ) (B). Typical impedance response of sensors at different $\mathrm{HAuCl}_{4}$ concentration to the expired breath of a healthy volunteer after ingestion of raw garlic. Redrawn and adapted with permission from Ref. [68] 


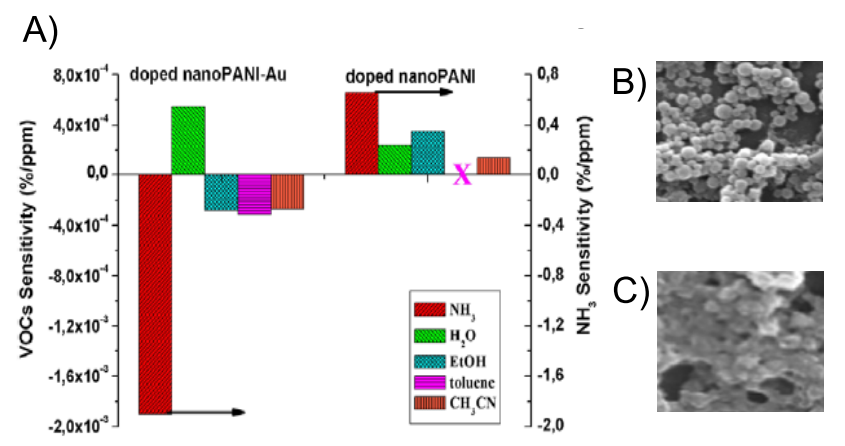

Figure 15: A): Sensitivity of nanoPANI-Au and nanoPANI for ammonia, ethanol, toluene and acetonitrile. B): SEM image of nanoPANI-Au composite obtained from osmosis-based method. (nanoparticles with diameters in the range from 180 to $220 \mathrm{~nm}$ ). C): SEM image of nanoPANI. Redrawn and adapted with permission from Ref. [69] 

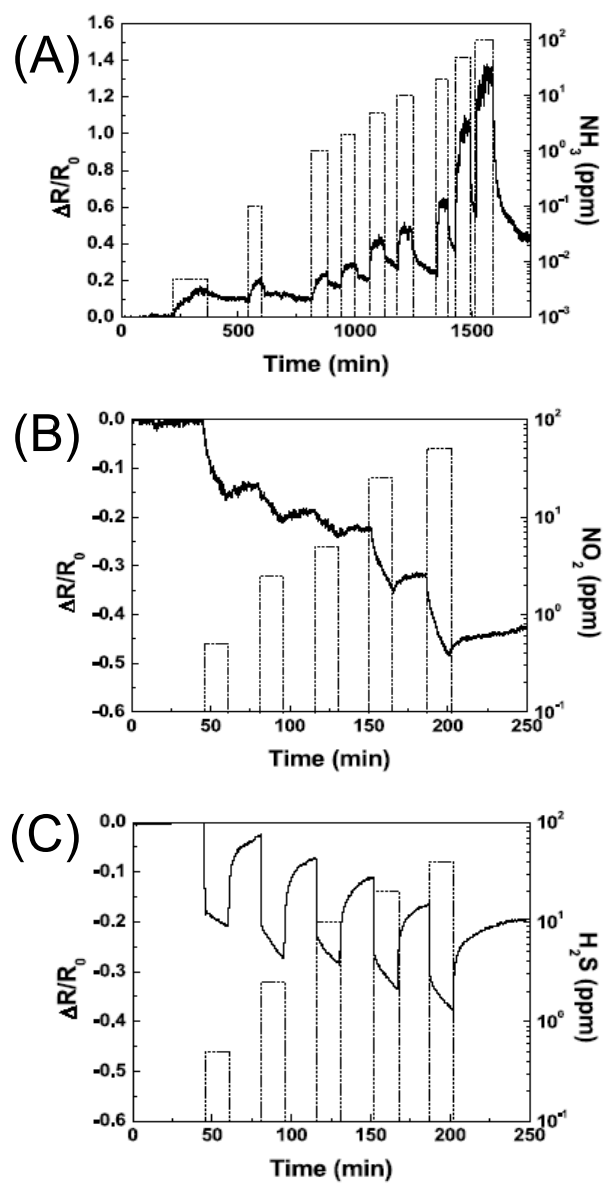

Figure 16: Resistance change $\Delta R / R_{0}$ (solid line) and analyte gas concentration (dashed line) as a function of time upon the exposure of different gases. (A): $\mathrm{NH}_{3} ;(\mathrm{B}): \mathrm{NO}_{2} ;(\mathrm{C})$ : $\mathrm{H}_{2} \mathrm{~S}$. Redrawn and adapted with permission from Ref. [70] 


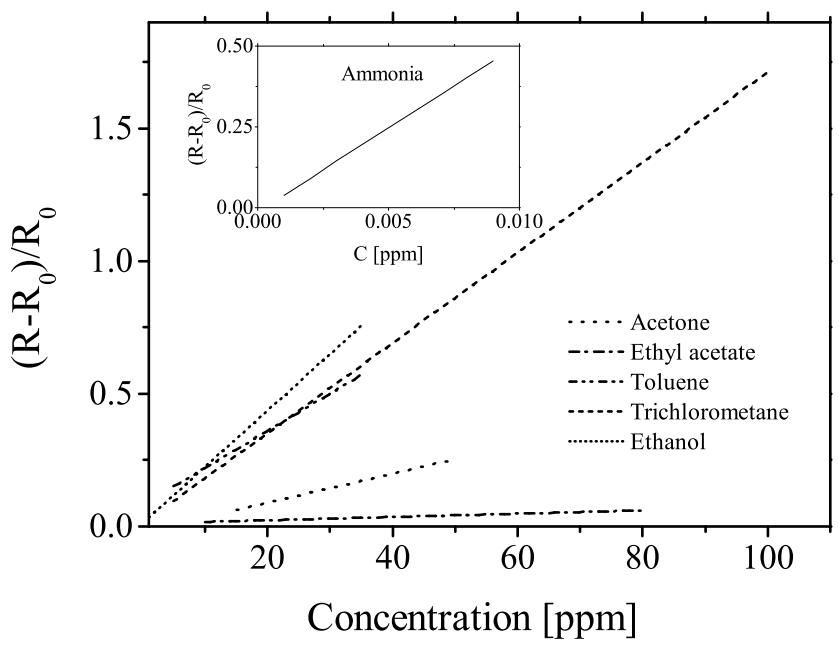

Figure 17: Response to various volatile organic compounds for PANI coating onto porous non-woven fabrics. Redrawn and adapted with permission from Ref. [76] 


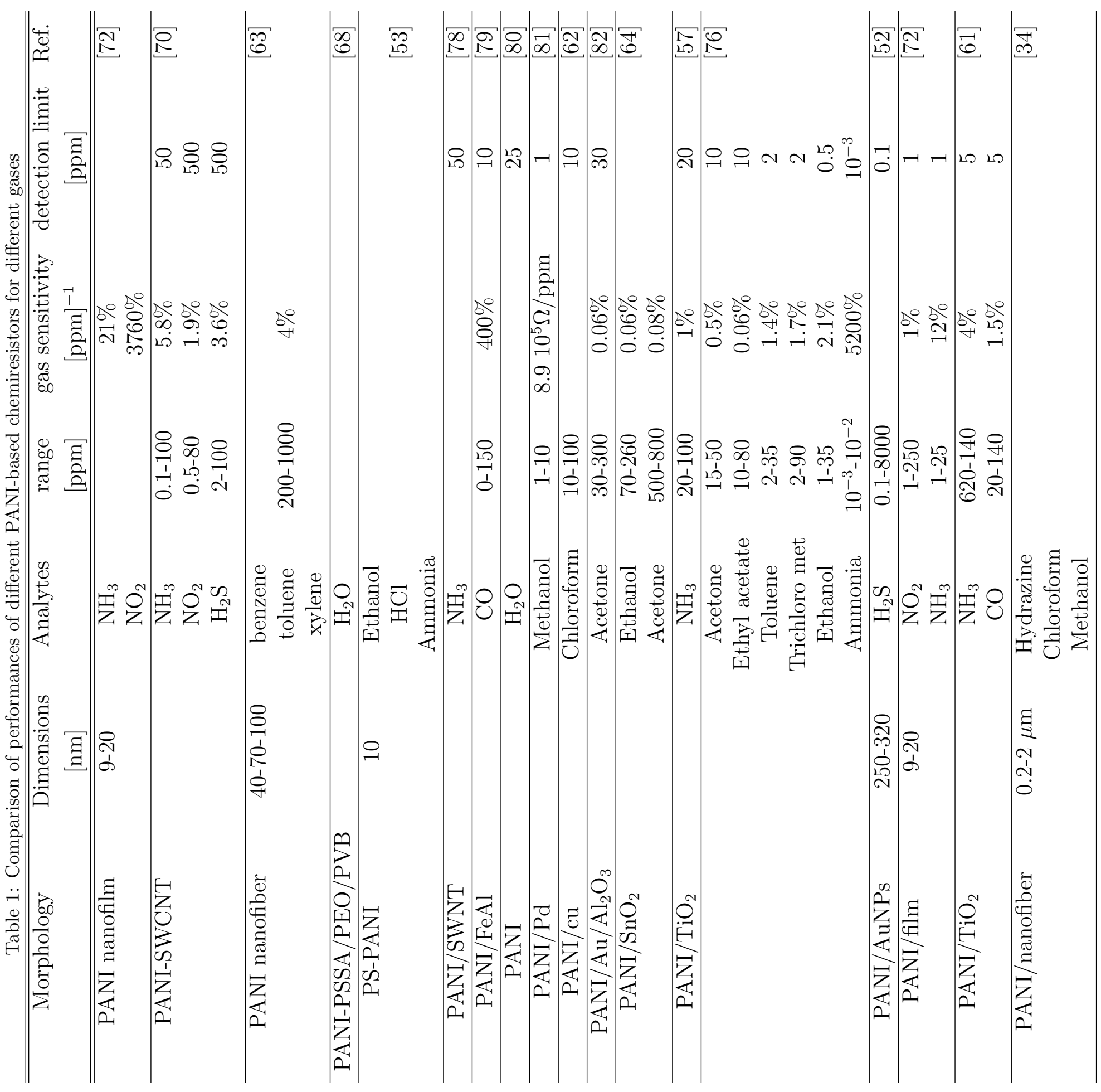




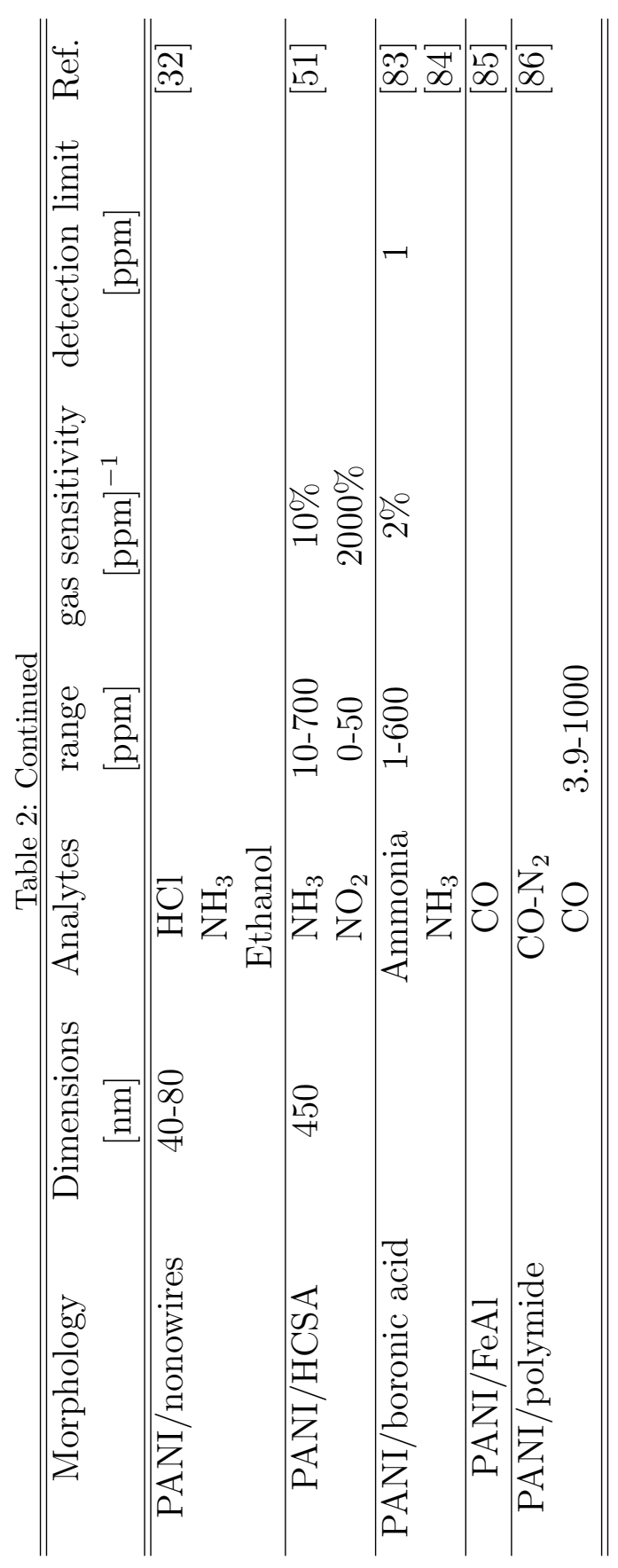




\section{References}

[1] Nylabder, C., Armgrath, M., Lundstrom, I.. An ammonia detector based on conducting polymers. In: Proc. Int. Meeting on Chemical Sensors. Fukuota, Japan; 1983, p. 203-207.

[2] Heeger, A.J.. Handbook of conducting polymers; vol. II. Marcel Dekker, New York; 1986.

[3] Bakker, E., Qin, Y.. Electrochemical sensors. Anal Chem 2006;78:3965-3983.

[4] Stetter, J.R., Li, J.. Amperometric gas sensors: a review. Chem Rev 2008;108:352-366.

[5] Wang, J.. Nanomaterial-based electrochemical biosensors. Analyst 2005; 130:421-426.

[6] Pumera, M., Sanchez, S., Ichinose, I., Tang, J.. Elettrochemical biosensors. Sens Actuators B 2007;123:1195-1205.

[7] Xiao, Y., Li, C.M.. Nanocomposites: from fabrication to electrochemical applications. Electroanalysis 2008;20:648-662.

[8] Reshetilov, A.N., Bezborodov, A.M.. Nanotechnology biosensors research. Appl Biochem Microbiol 2008;44:1-5.

[9] Jiemenez-Cadena, G., Riv, J., Rius, F.X.. Gas sensors based on nanostrucured materials. Analysts 2007;132:1083-1099.

[10] Venditti, I., D'Amato R. aand Russo, M.V., Falconieri, M.. Synthesis of conjugated polymeric nanobeads for photonic bandgap materials. Sensors and Actuators B 2007;126:35-40.

[11] Pantalei, S., Zampetti, E., Macagnano, A., Bearzotti, A., Venditti, I., Russo, M.V.. Enhanced sensory properties of a multichannel quarz crystal microbalance coated with polymeric nanobeads. Sensors 2007;7:2920-2928.

[12] Batagin-Neto, A., Bronze-Uhle, E., Fernandes, D., Fratoddi, I., Venditti, I., Decker, F., et al. Optical behavior of conjugated ptcontaining polymetallaynes exposed to gamma-ray radiation doses. J Phys Chem B 2011;115:8047-8053. 
[13] Fratoddi, I., Venditti, I., Cametti, C., Palocci, C., Chronopoulou, L., Marino, M., et al. Functional polymeric nanoparticles for dexamethasone loading and release. Colloids and Surfaces B 2012;93:59-66.

[14] Fratoddi, I., Bronze-Uhle, E.S., Batagin-Neto, A., Fernandes, D.M., Bodo, E., Batocchio, C., et al. Structural changes of conjugated ptcontaining polymetallaynes exposed to gamma-ray radiation doses. J Phys Chem A 2012;116:8768-8774.

[15] Fratoddi, I., Marghella, G., Venditti, I., Ferro, D., Russo, M.V.. Organometallic pt(ii) containing polymer as silver protection against sulfide tarnishing. J Appl Polym Sci 2013;128:304-309.

[16] Bearzotti, A., Macagnano, S., Pantalei, E., Zampetti, E., Venditti, I., Fratoddi, I., et al. Alcohol vapor sensory properties of nanostructured conjugated polymers. J Phys: Condens Matter 2008;20:474207-6pp.

[17] Quartarone, E., Mustarelli, P., Magistris, A., Russo, M.V., Fratoddi, I., Furlani, A.. Investigation by impedance spectroscopy on the behavior of poly-(n,n dimethyl propargylamine) as humidity sensors. Sodid State Ionics 2000;136-137:667-670.

[18] Altamura, P., Bearzotti, A., D'Amico, A., Foglietti, V., Fratoddi, I., Furlani, A., et al. Elecrical and morphological characterization of new $\pi$-conjugated polymer films as gas sensors. Mat Sci Eng C 1998;C5:217221.

[19] Bearzotti, A., Fratoddi, I., Palummo, L., Petrocco, S., Furlani, A., Lo Sterzo, C., et al. Highly ethynylated polymers: synthesis and applications for humidity sensors. Sensors and Actuators B 2001;76:316321.

[20] Caliendo, C., Fratoddi, I., Russo, M.V.. Sensitivity of a platinumpolyyne sensor to low relative humidity and chemical vapors. Appl Phys Lett 2002;80:4849-4851.

[21] Fratoddi, I., Altamura, P., Bearzotti, A., Furlani, A., Russo, M.V.. Electrical and morphological characterization of poly(mono substituted) acetylene based membranes: application as humidity and organic vapour sensors. Thin Solid Films 2004;458:292-298. 
[22] Palummo, L., Fratoddi, I., Russo, M.V., Bearzotti, A.. Resistive type sensor for humidity and short alcohol detection. Swnsor Letters 2004;2:205-210.

[23] Caliendo, C., Contini, G., Fratoddi, I., Irrera, S., Pertici, P., Scavia, G., et al. Nanostructured organometallic polymer and palladium/polymer hybrid: surface investigation and sensitivity to relative humidity and hydrogen in surface acoustic wave sensors. Nanotechnology 2007;18:125504-7pp.

[24] Venditti, I., Fratoddi, I., Bearzotti, A.. Self-assembled copolymeric nanoparticles as chemically interactive materials for humidity sensors. Nanotechnology 2010;21:355502-8pp.

[25] Yoon, H.. Current trends in sensors based on conducting polymer nanomaterials. Nanomaterials 2013;3:524-549.

[26] Huang, Y.J., Choi, Y.K.. Chemical sensors based on nanostructured materials. Sensors and Actuators B 2007;122:659-671.

[27] Huang, W.S., Humphrey, B.D., Mac Diarmid, A.G.. Polyaniline, a novel conducting polymer. morphology and chemistry of its oxidation and reduction in aqueous solution. J Chem Soc Faraday Trans 1 1986;82:2385-2400.

[28] Boyle, A., Genies, E.H., Lapkowski, M.. Application of the electronic conducting polymers as sensors: polyaniine in the solid state for detection of solvent vapors and polypyrrole for detection of biological ions in solution. Synth Met 1989;28:769-774.

[29] Hu, H., Trejo, M., Saniger, J.M., Garcia-Valenzuela, A.. Adsorption kinetics of optochemical $\mathrm{nh}_{3}$ gas sensing with semiconductor polyaniline film. Sensors and Actuators B 2002;82:14-23.

[30] Li, N., Li, X., Geng, W., Zhang, T., Zuo, Y., Qiu, S.. Synthesis and humidity sensitivity of conducting polyaniline in sba. J Appl Polym Sci 2004;93:1597-1601.

[31] Aguilar, A.D., Firzani, E.S., Li, X., Tao, N., Nagahara, L.A., Amlani, I., et al. Chemical sensors using peptide-funtionalized conducting polymer nanojunction array. Appl Phys Lett 2005;87:193108-3pp. 
[32] Wang, J., Chan, S., Carlson, R.R., Luo, Y., Ge, G.L., Ries, R.S., et al. Electrochemically fabricated polyaniline nanoframework electrode junctions that function as resistive sensor. Nano Lett 2004;4:1693-1697.

[33] Huang, J., Virji, S., Weiller, B.H., Kaner, R.B.. Nanostructured polyaniline sensors. Chem Eur J 2004;10:1314-1319.

[34] Virji, S., Huang, J., Kaner, R.B., Weiller, B.H.. Polyaniline nanofiber gas sensors: examination of response mechanisms. Nano Lett 2004;4:491-496.

[35] Ma, X.F., Li, G., Wang, M., Cheng, Y.N., Bai, R., Chen, H.Z.. Preparation of a nanowire structured polyaniline composite and gas sensityvity studies. Chem Eur J 2006;12:3254-3260.

[36] Zhang, T., Mubeen, S., Yoo, B., Myung, N.V., Deshusses, M.A.. A gas nanosensor unaffected by humidity. Nanotechnology 2009;20:225509-5pp.

[37] Yan, X.B., Han, Z.J., Yang, Y., Tay, B.K.. $\mathrm{No}_{2}$ gas sensing with polyaniline nanofibers synthesized by a facile aqueous/organic interfacial polarization. Sensors and Actuators B 2007;123:107-113.

[38] Virji, S., Kaner, R., Weiller, B.. Hydrogen sensors based on conductivity changes in polyaniline nanofibers. J Phys Chem B 2006;110:2226622270 .

[39] Babu, V.J., Vempati, S., Ramakrishna, S.. Conducting polyanilineelectrical charge transportation. Materials Sciences and Applications 2013;4:1-10.

[40] Huang, J., Kaner, R.B.. Nanofiber formation in the chemical polymerization of aniline. a mechanicistic study. Angew Chem Int Ed 2004;43:5817-5821.

[41] Lin, C., Hwang, B., Lee, C.. Characteristics and sensing behavior of electrochemically codeposited polypyrrole-poly(vinyl alcohol) thin film exposed to ethanol vapors. J Appl Polym Sci 1999;73:2079-2087.

[42] Lin, C., Liu, S., Hwang, B.. Study of the actions of btex compounds on polypyrrole film as a gas sensor. J Appl Polym Sci 2001;82:954-961. 
[43] Hwang, B., Yang, J., Lin, C.. A microscopic gas-sensing model for ethanol sensors based on conductive polymer composites from polypyrrole and poly(ethylene oxide). J Electrochem Soc 1999;146:1231-1236.

[44] Sakai, G., Matsunaga, N., Shimanoe, K., Yamazoe, N.. Theory of gasdiffusion controlled sensitivity for thin film semiconductor gas sensors. Sensors and Actuators B 2001;80:125-131.

[45] Gardner, J.W., Bartlett, P.N., Pratt, K.F.E.. Modeling the gas sensitive conducting polymer devices. IEE Proc Circuits \& Devices and Systems 1995;142:321-333.

[46] Gardner, J.W., Bartlett, P.N.. Design of conducting polymer gas sensors: modeling and experiments. Synth Met 1994;57:3665-3670.

[47] McGovern, S.T., Spinks, G.M., Wallace, G.G.. Micro-humidity sensors based on a processable polyaniline blend. Sensors and Actuators B 2005;107:657-665.

[48] Sakurai, Y., Jung, H.S., Shimanouchi, T., Inoguchi, T., Morita, S., Kuboi, R., et al. Novel array type gas sensors using conducting polymers and their performance for gas identification. Sensors and Actuators B 2002;83:270-275.

[49] Matsubara, I., Hosono, K., Murayama, N., Shin, W., Izu, N.. Synthesis and gas sensing of polypyrrole- $\mathrm{moO}_{3}$-layered nanohybrids. Bull Chem Soc Jpn 2004;77:1231-1237.

[50] Vercelli, B., Zecchin, S., Comisso, N., Zotti, G., Berlin, A., Dalcanale, E., et al. Solvoconductivity of polycojugated polymers: the role of polymer oxidation degree and solvent electrical permitivity. Chem Mat 2002;14:4768-4774.

[51] Zhang, Y., Kim, J.J., Chen, D., Tuller, H.L., Rutlegde, G.C.. Electrospun polyaniline fibers as highly sensitive room temperature chemiresistive sensors for ammonia and nitogen dioxide gases. Adv Funct Mat 2014;24:4005-4014.

[52] Shirsat, M.D., Baugar, M.A., Deshusses, M.A., Myung, N.V., Mulchandani, A.. Polyaniline nanowire-gold nanoparticle hybrid network based chemiresistive hydrogen sulfide sensor. Appl Phys Lett 2009;94:083502-1/3. 
[53] Yang, L.Y., Liau, W.B.. Environmental responses of nanostructured polyaniline films based on polystyrenepolyaniline coreshell particles. Mat Chem and Phys 2009;115:28-32.

[54] Svetlicic, V., Schmidt, A.J., Miller, L.L.. Conductometric sensors based on the hypersensitive response of plasticized polyaniline films to organic vapors. Chem Mat 1998;10:3305-3307.

[55] Athawale, A.A., Kulkarni, M.V.. Polyaniline and its substituted derivatives as sensors of aliphatic alcohols. Sensors and Actuators B 2000;67:173-177.

[56] Fowler, J., Virji, S., Kaner, R., Weiller, B.. Hydrogen detection by polyaniline nanofibers on gold and platinum electrodes. J Phys Chem C 2009;113:6444-6449.

[57] Pawar, S.G., Chougule, M.A., Sen, S., Patil, V.B.. Development of nanostructured polyanilinetitanium dioxide gas sensors for ammonia recognition. J Appl Polym Sci 2012;125:1418-1424.

[58] Ram, M.K., Yavuz, O., Lahsangah, V., Aldissi, M.. Co gas sensing from ultra thin nano-composite conducting polymer film. Sensors and Actuators B 2005;106:750-757.

[59] Sadek, A.Z., Wlodarski, W., Shin, K., R., B., Kalantarzadek, K.. A layered surface acoustic wave gas sensor based on polyaniline/ $\mathrm{in}_{2} \mathrm{O}_{3}$ nanofivbre composite. Nanotechnology 2006;17:4488-4492.

[60] Fratoddi, I., Zampetti, E., Venditti, I., Batocchio, C., Russo, M.V., A., M., et al. Platinum nanoparticles on electrospun titania nanofibers as hydrogen sensing materials working at room temperature. Nanoscale 2014;6:9177-9184.

[61] Tai, H., Jiang, Y., Xu, G., Yu, J., Chen, X.. Fabrication and gas sensitivity of polyaniline-titanium dioxide nanocomposite thin film. Sensors and Actuators B 2007;125:644-650.

[62] Sharma, S., Nirkhe, C., Pethkar, S., Athawale, A.A.. Chloroform vapor sensor based on copper-polyaniline nanocomposite. Sensors and Actuators B 2002;85:131-136. 
[63] Li, W., Hoa, N.D., Cho, Y., Kim, D., Kim, J.S.. Nanofibers of conducting polyaniline for aromatic organic compound sensor. Sensors and Actuators B 2008;148:132-138.

[64] Geng, L., Zhao, Y., Huang, X., Wang, S., Zhang, S., Wu, S.. Characterization and gas sensitivity study of polyaniline $/ \mathrm{sno}_{2}$ hybrid material prepared by hydrothermal route. Sensors and Actuators B 2007;120:568-572.

[65] Do, J.S., Chang, W.B.. Amperometric nitrogen dioxide gas sensor based on pan/au/nafion prepared by constant current and cyclic voltammetry. Sensors and Actuators B 2004;101:97-106.

[66] MacDiarmid, A.G., Jones, W.E., Norris, I.D., Gao, J., Johnson, A.T., Pinto, N.I., et al. Electrolitically generated nanofibers of electronic polymers. Synth Met 2001;119:27-30.

[67] Briseno, A.L., Gao, T., Huang, J., Hopkin, A.R., Sisk, B., Kaner, R.B., et al. Detection of n-butylamine vaporsby morphologically different polyaniline chemirestive detectors. Polym Preprints 2003;44:140-...

[68] Lin, C., Hayashi, K., Toko, K.. Au nanoparticle decorated polyaniline nanofibers sensor for detecting volatile sulfur compounds in expired breath. Sensors and Actuators B 2012;161:504-509.

[69] Venditti, I., Fratoddi, I., Russo, M.V., Baerzotti, A.. A nanostructured composite based on polyaniline and gold nanoparticles: synthesis and gas sensing properties. Nanotechnology 2013;24:155503-7pp.

[70] Lim, J.H., Phiboolsirichit, N., Mubeen, S., Deshusser, M.A., Mulehandani, A., Myung, N.V.. Electrical and gas sensing properties of polyaniline functionalized single-walled carbon nanotubes. Nanotechnology 2010;21:075502-7pp.

[71] Lin, Q., Li, Y., Youg, M.. Polyaniline nanofiber humidity sensors prepared by electrospinning. Sensors and actuators B 2012;161:967-972.

[72] Srinives, S., Sarkar, T., Mulchandani, A.. Nanothin polialinine film for highly sensitive chemiresistive gas sensing. Electroanalysis 2013;25:1439-1445. 
[73] Agbor, N.E., Petty, M.C., Monkmann, A.P., Havtr, M.. Langmuirblodgett film of polyaniline. Sensors and Actuators B 1995;28:37893794 .

[74] Mekki, A., Joshi, N., Singh, A., Salmi, Z., Jha, P., Decorse, P., et al. $\mathrm{H}_{2}$ s sensing using in situ-polymerized polyaniline-silver nanocomposite films on flexible substrates. Org Electronics 2014;15:71-81.

[75] Wanna, Y., Srisukhumbowornchai, N., Tauntranont, A., Wisitsoraat, A., Thavarungkul, N., Singjai, P.. The effect of carbon nanotube dispersion on co gas sensing characteristics of polyaniline gas sensor. J Nanosci Nanotechnol 2006;6:3893-3896.

[76] Qi, J., Xinxin, X., Liu, X., Lau, K.T.. Fabrication of texile based conductometric polyaniline gas sensors. Sensors and Actuators B 2014;202:732-740.

[77] Xia, L., Wei, Z., Wan, M.. Conducting polymer nano structures and their applications in biosensors. J Colloid Interface Sci 2010;341:1-11.

[78] Zhang, T., Nix, M.B., Deshusses, M.A., Myung, N.V.. Electrochemically functionalized single-walled carbon nanotube gas sensor. Electroanalysis 2006;18:1153-1158.

[79] Dixit, V., Misra, S.C.K., Sharma, B.S.. Carbon monoxide sensitivity of vacuum deposited polyaniline semiconducting thin films. Sensors and Actuators B 2005;104:903-93.

[80] Li, G., Martinez, C., Semancik, S.. Controlled electrophoretic patterning of polyaniline from colloidal suspensions. J Am Chem Soc 2005; 127:4903-4909.

[81] Athawal, A.A., Bhagwat, S.V., Katre, P.P.. Nanocomposite of pdpolyaniline as a selective methanol sensor. Sensors and Actuators B 2006;114:263-267.

[82] Do, J.S., Wang, S.H.. On the sensitivity of conductometric acetone gas sensor based on polypyrrole and polyaniline conducting polymers. Sensors and Actuators B 2013;114:39-46. 
[83] Chabukswar, V.V., Pethkar, S., Athawale, A.A.. Acrylic acid doped polyaniline as a ammonia sensor. Sensors and Actuators 2001;77:657663.

[84] English, J.T., Deore, B.A., Freund, M.S.. Biogenic amine vapour detection using poly(anilineboronic acid) films. Sensors and Actuators B 2006;115:666-671.

[85] Misra, S.C.K., Mathur, P., Srivastava, B.K.. Vacuum deposited monocrystalline polyaniline thin film sensors for detection of carbon monoxide. Sensors and Actuators A 2004;114:30-35.

[86] Watcharaphalakorn, S., Ruangchuay, L., Chotpattananont, D. Polyaniline/polymide blends as gas sensors and electrical conductivity response to $c 0-\mathrm{n}_{2}$ mixtures. Polym Int 2005;54:1126-1133. 